\title{
Chronic Portal-Systemic Shunt Encephalopathy in a Hemodialysis Patient Treated with Balloon-Occluded Retrograde Transvenous Obliteration
}

\author{
Ryota Yasukawa $^{a} \quad$ Fumihiro Akiyama $^{\mathrm{b}}$ Takashi Tsukishiro $^{\mathrm{b}}$ \\ Ichiei Narita ${ }^{a}$ \\ ${ }^{a}$ Division of Clinical Nephrology and Rheumatology, Niigata University Graduate School \\ of Medical and Dental Sciences, Niigata, and ${ }^{\mathrm{b}}$ Department of Internal Medicine, Itoigawa \\ General Hospital, Itoigawa, Japan
}

\section{Key Words}

Chronic portal-systemic shunt encephalopathy - Balloon-occluded retrograde transvenous obliteration · Hemodialysis

\begin{abstract}
We report a case of chronic portal-systemic shunt encephalopathy in a 79-year-old female hemodialysis patient with end-stage renal disease. Approximately 1 month before admission, she occasionally had a discrepant conversation. It was considered that hepatic encephalopathy was caused by an increase in the ammonia level in the blood flow of the shunt, which had been diagnosed 7 years previously between the splenic vein and the left renal vein. On admission, disturbed consciousness and an elevated serum ammonia level $(221 \mu \mathrm{g} / \mathrm{dl})$ were observed. No change in the shunt diameter was noted. Consciousness improved with conservative treatment, whereas hyperammonemia remained. Balloon-occluded retrograde transvenous obliteration (B-RTO) was performed on the shunt. As a result, hyperammonemia resolved immediately, and the level of ammonia was maintained at approximately $60 \mu \mathrm{g} / \mathrm{dl}$. The patient often complained of drug-induced constipation; therefore, an increase in the intra-abdominal pressure in addition to ammonia production in the intestinal tract was suspected as the cause of encephalopathy. More than 23 months have passed since the BRTO therapy, and no symptoms of encephalopathy have been observed yet.
\end{abstract}




\section{Introduction}

Hepatic encephalopathy is usually observed in patients with liver failure; however, hepatic encephalopathy with no evidence of liver failure has recently been reported in dialysis patients with portal-systemic shunts (PSS) [1-3]. This condition is called chronic portal-systemic shunt encephalopathy (CPSE). Some proposed etiologies of PSS include natural constitution [4], adhesion [5], and portal hypertension [6]. In addition, bodily fluid in dialysis patients is generally excessive, contributing to the development of this condition [7]. However, Nishimoto et al. [8] also reported that, in reality, the etiology of PSS was unclear. Here, we report a dialysis patient with hepatic encephalopathy, which was caused by an increase in the ammonia level in the blood flow of the shunt between the splenic vein and left renal vein and was successfully treated by balloon-occluded retrograde transvenous obliteration (B-RTO).

\section{Case Report}

A 79-year-old female, who had been receiving regular hemodialysis treatment for 15 years due to end-stage renal disease caused by immunoglobulin A nephropathy, was admitted to our hospital because of mild disturbance of consciousness. Approximately 1 month before admission, she occasionally had a discrepant conversation. Seventeen years before admission, she was diagnosed with autoimmune hepatitis based on a liver biopsy. Seven years before admission, a shunt between the splenic vein and left renal vein was detected. She had no history of excessive alcohol consumption or abdominal surgeries.

Physical examination on admission revealed the following: height $152 \mathrm{~cm}$, body weight $54.8 \mathrm{~kg}$ (dry weight $53.5 \mathrm{~kg}$ ), blood pressure $151 / 86 \mathrm{~mm} \mathrm{Hg}$, pulse rate $82 / \mathrm{min}$ and regular, temperature $36.5^{\circ} \mathrm{C}$, no anemia or jaundice, consciousness Glasgow Coma Scale score of 14 (E4V4M6), clear lung fields, no audible heart murmur, abdominal wall flattened with no muscle hoarding or tenderness, liver not palpable, spleen not enlarged, no edema in the lower legs, and tremor in the upper limbs with no paralysis. Laboratory examinations (table 1) revealed hyperammonemia $\left(\mathrm{NH}_{3} 221 \mu \mathrm{g} / \mathrm{dl}\right)$, but no liver damage or coagulation disorder was observed. Echocardiography showed normal valvular function with a left ventricular ejection fraction of $73 \%$. The inferior vena cava diameter was also found to be normal. Chest X-ray revealed a cardiothoracic ratio of $56.2 \%$. No abnormalities were found on head computed tomography. Abdominal computed tomography with image contrast medium (fig. 1) revealed a rough liver surface and a shunt of unchanged diameter since its diagnosis 7 years earlier. Class A liver function was determined according to the Child-Pugh classification system (total bilirubin $0.5 \mathrm{mg} / \mathrm{dl}$, albumin $3.2 \mathrm{~g} / \mathrm{dl}$, and prothrombin time $88.0 \%$ with no ascites). Therefore, hepatic encephalopathy with hyperammonemia due to an increase in the ammonia level in the blood flow of the shunt was suspected. Disturbed consciousness improved after 24-hour treatment with cathartics and regular hemodialysis, but the ammonia level was still found to be $182 \mu \mathrm{g} / \mathrm{dl}$ with tremor in the upper limbs. Three days after admission, no symptoms of hyperammonemia were observed though the ammonia level was found to be $155 \mu \mathrm{g} / \mathrm{dl}$. Eight days after admission, the ammonia level was found to be $101 \mu \mathrm{g} / \mathrm{dl}$. The patient was discharged on hospital day 15. After that, she did not have any hyperammonemic complications, though her ammonia level was found to be between 62 and $112 \mu \mathrm{g} / \mathrm{dl}$. Two months after discharge, angiography revealed blood flow into the inferior vena cava through the left renal vein via the shunt from the splenic vein. B-RTO was therefore performed with ethanolamine oleate to occlude the shunt (fig. 2). The ammonia 
level was found to be $104 \mu \mathrm{g} / \mathrm{dl}$ before B-RTO, and the next day it was found to be $54 \mu \mathrm{g} / \mathrm{dl}$. After that, the ammonia level was maintained at approximately $60 \mu \mathrm{g} / \mathrm{dl}$.

More than 23 months have passed since the B-RTO therapy, and no symptoms of encephalopathy have been observed. In addition, esophagogastroduodenoscopy revealed no gastric or esophageal varices before or after B-RTO.

\section{Discussion}

Some etiologies of PSS have been proposed [4-7]. In our case, the patient had no history of abdominal surgery or trauma; therefore, her PSS was thought to be congenital. In general, hemodialysis patients suffer from constipation, which contributes to encephalopathy through acceleration of $\mathrm{NH}_{3}$ production. In addition, constipation might increase the shunt flow by changing the hemodynamics in the abdominal area. In other words, due to constipation, more blood from the portal circulation might go directly to the systemic circulation, bypassing the liver.

Medication for hyperphosphatemia, hyperkalemia, and secondary hyperparathyroidism, characteristic of dialysis patients, frequently leads to constipation. In the present case, treatment with precipitated calcium carbonate, lanthanum carbonate hydrate, calcium polystyrene sulfonate, and alfacalcidol might be the cause of her constipation. In fact, the patient often experienced constipation. In the initial stages of encephalopathy, ammonia production in the intestinal tract might have temporally increased more than normal [9]. In addition, constipation possibly caused an increase of the shunt flow because of changes in hemodynamics in the abdominal area. The reasons for this are as follows. (1) In general, intrarectal pressure is approximately less than $5 \mathrm{~mm} \mathrm{Hg}$. However, strain pressure raises intrarectal pressure to approximately $15 \mathrm{~mm} \mathrm{Hg}$ [10]. Intrarectal pressure is substituted for intra-abdominal pressure (IAP) in urodynamic practices [11]. Elevation of IAP causes a decrease in the portal cross-sectional area and flow as can be seen in laparoscopic examinations of liver cirrhosis patients. On laparoscopic examinations, IAP was observed to increase to approximately $15 \mathrm{~mm} \mathrm{Hg} \mathrm{[12].} \mathrm{(2)} \mathrm{Peritoneal} \mathrm{dialysis} \mathrm{possibly} \mathrm{contributes} \mathrm{to} \mathrm{the}$ development of CPSE with elevation of IAP [13]. Thus, repeated elevation of IAP with strain pressure seemed to increase the congenital shunt size and to cause a relative decrease in portal flow and a concomitant increase in the PSS flow.

In Japan, 12 cases of CPSE in dialysis patients have been reported [1-3]. The average age of the patients was 62 years, and the sex ratio was 6:6. Most of these patients developed CPSE after more than 1 year of maintenance hemodialysis. However, 3 of them had CPSE immediately after starting hemodialysis, supporting the possibility that the change in hemodynamics due to hemodialysis causes hyperammonemia. Ubara et al. [2] suggested that removing excess fluid slowly via peritoneal dialysis was superior to hemodialysis in the treatment of CPSE because relatively rapid reduction in venous pressure in hemodialysis may cause an increase in the PSS flow. In contrast, Paraíso et al. [13] reported that increased IAP because of peritoneal dialysis causes an increase in the PSS flow, and recovery from CPSE was achieved via hemodialysis. In our case, we speculate that increased PSS flow was caused by an increase in IAP rather than by a reduction of venous pressure because an immediate recovery of consciousness was observed after hemodialysis.

In addition, it has been reported that alkalemia due to bicarbonate dialysis accelerates the permeability of ammonia via the blood-brain barrier [14], and the aged brain is intolerant of hyperammonemia [15]. Bicarbonate dialysis had been performed in our patient for low blood pressure, which might have occurred because of acetic acid from the dialysis 
fluid. Thus, the content of the dialysis fluid might affect the development of encephalopathy to some degree.

Conservative therapy for CPSE includes restriction of protein intake, infusion of branched-chain amino acids, and oral administration of lactulose and neomycin, whereas curative therapy includes blocking the PSS flow by surgical or other interventional means. BRTO provides a minimally invasive means of embolization with ethanolamine oleate, which is a curative agent. In the present case, B-RTO was chosen as a less invasive alternative to surgical intervention because disturbed consciousness resolved following conservative therapies, and because the patient had been on long-term hemodialysis.

In summary, an increase in the ammonia level in the blood flow of the shunt, along with constipation, seemed to be the main cause of encephalopathy in our patient. Even if a patient has liver cirrhosis with hepatic encephalopathy, liver cirrhosis should not be considered to be the only cause of hyperammonemia. PSS, which may be cured, should also be considered. In addition, it is important to manage constipation and excess bodily fluid, which are characteristic of hemodialysis patients, in order to prevent recurrence.

\section{Disclosure Statement}

The authors have declared that no conflict of interest exists.

\section{References}

1 Shimono J, Tsuji H, Azuma K, Hashiguchi M, Fujishima M: Recurring encephalopathy abolished by gastrorenal shunt ligation in a diabetic hemodialysis patient. Am J Gastroenterol 1998;93:270-272.

$\checkmark 2$ Ubara Y, Hoshino J, Tagami T, Sawa N, Katori H, Takemoto F, Matsuda M, Hara S, Takaichi K: Hemodialysisrelated portal-systemic encephalopathy. Am J Kidney Dis 2004;44:e38-e42.

3 Kojima F, Ueda M, Saitou M, Tanaka Y, Karakama Y, Koshiishi T, Nitta K, Akida T: Balloon-occluded retrograde transvenous obliteration was effective for hyperammonemia caused by chronic portal-systemic shunt encephalopathy in hemodialysis patient - a case report. J Jpn Soc Dial Ther 2012;45:267-272.

4 Edwards EA: Functional anatomy of the porta-systemic communications. AMA Arch Intern Med 1951;88:137-154.

5 Moncure AC, Waltman AC, Vandersalm TJ, Linton RR, Levine FH, Abbott WM: Gastrointestinal hemorrhage from adhesion-related mesenteric varices. Ann Surg 1976;183:24-29.

6 Takashi M, Igarashi M, Ueno M, Shinichi H, Nobuaki G, Okuda K: A case of portal-systemic encephalopathy without portal hypertension. Acta Hepatol Jpn 1982;23:546-552.

7 Yoshimitsu T, Hirakata H, Kanai H, Kubo M, Ishida I, Ando T, Yoshida T, Tusji H, Kuroiwa T, Fujimi S, Okuda S, Fujishima M: Chronic portal-systemic shunt encephalopathy (CPSE) in a hemodialysis patient: a case report. J Jpn Soc Dial Ther 1997;30:999-1005.

-8 Nishimoto Y, Hoshino H, Sato S, Oguri A, Yamada M, Nishimura D, Katada N, Sano H, Kato K: Extrahepatic portosystemic venous shunt without portal hypertension. Intern Med 1997;36:886-889.

$\rightarrow$ Losowsky MS, Scott BB: Hepatic encephalopathy. Br Med J 1973;3:279-281.

10 Kuwahara Y, Imai M, Yoshida T, Shimizu Y, Nishimura N, Yokoyama K, Iwase S, Hirai M, Sugenoya J: Valsalva maneuver effects on heart rate, blood pressure, and intrarectal pressure - supine versus sitting. Auton Neurosci 2011;165:211-212.

11 Schäfer W, Abrams P, Liao L, Mattiasson A, Pesce F, Spangberg A, Sterling AM, Zinner NR, van Kerrebroeck P: Good urodynamic practices: uroflowmetry, filling cystometry, and pressure-flow studies. Neurourol Urodyn 2002;21:261-274.

12 Takagi S, Kaneko H, Tamura A, Jobara N, Katagiri T, Tsuchiya M, Ishii T, Shiba T: The influence of carbon dioxide pneumoperitoneum on portal blood flow in patients with liver cirrhosis. Jpn J Gastroenterol Surg 2001;34:75-82.

13 Paraíso V, Francos M, Rodríguez-Berzosa F, Felipe C, López-Valdés E, Martín R, Blázquez J, Chacón C, Fidalgo A, Martín J: Portosystemic encephalopathy in a patient treated with peritoneal dialysis. Am J Kidney Dis 2007;49:854-858.

14 Inoue K, Yoshiba M: Blood purification for patients with chronic renal failure accompanied with severe liver disease. Nippon Rinsho 2004;62:66-69. 
15 Kerlan RK Jr, Sollenberger RD, Palubinskas AJ, Raskin NH, Callen PW, Ehrenfeld WK: Portal-systemic encephalopathy due to a congenital portocaval shunt. AJR Am J Roentgenol 1982;139:1013-1015.

Table 1. Laboratory findings on admission

\begin{tabular}{|c|c|c|c|c|c|c|c|c|c|}
\hline \multicolumn{2}{|c|}{ Hematology } & \multicolumn{2}{|c|}{ Blood gas analysis } & \multicolumn{6}{|c|}{ Blood chemistry } \\
\hline WBC & $5,500 / \mu \mathrm{l}$ & $\mathrm{pH}$ & 7.424 & T-bil & $0.5 \mathrm{mg} / \mathrm{dl}$ & $\mathrm{K}$ & $4.1 \mathrm{mEq} / \mathrm{l}$ & BCAA/AAA & 1.2 \\
\hline (neu. & $43.7 \%)$ & $\mathrm{PCO}_{2}$ & 45.1 Torr & ALT & $19 \mathrm{IU} / \mathrm{l}$ & $\mathrm{Cl}$ & $101 \mathrm{mEq} / \mathrm{l}$ & Ferritin & $49.3 \mathrm{ng} / \mathrm{ml}$ \\
\hline $\mathrm{RBC}$ & $365 \times 10^{4} / \mu \mathrm{l}$ & $\mathrm{HCO}_{3}$ & $28.9 \mathrm{mEq} / \mathrm{l}$ & AST & $11 \mathrm{IU} / \mathrm{l}$ & $\mathrm{Mg}$ & $2.7 \mathrm{mg} / \mathrm{dl}$ & Serum iron & $38 \mu \mathrm{g} / \mathrm{dl}$ \\
\hline $\mathrm{Hb}$ & $11.4 \mathrm{~g} / \mathrm{dl}$ & $\mathrm{BE}$ & $3.8 \mathrm{mEq} / \mathrm{l}$ & $\gamma$-GTP & $20 \mathrm{IU} / \mathrm{l}$ & $\mathrm{Al}$ & $<10 \mu \mathrm{g} / \mathrm{l}$ & TIBC & $209 \mu \mathrm{g} / \mathrm{dl}$ \\
\hline $\mathrm{Ht}$ & $34.7 \%$ & & & LDH & $263 \mathrm{IU} / \mathrm{l}$ & Plasma & & HBsAg & negative \\
\hline \multirow[t]{11}{*}{ Platelets } & $20.1 \times 10^{4} / \mu \mathrm{l}$ & & & $\mathrm{CK}$ & $60 \mathrm{IU} / \mathrm{l}$ & glucose & $100 \mathrm{mg} / \mathrm{dl}$ & $\mathrm{HBcAb}$ & negative \\
\hline & & & & $\mathrm{Cr}$ & $8.35 \mathrm{mg} / \mathrm{dl}$ & CRP & $0.09 \mathrm{mg} / \mathrm{dl}$ & aPTT & $33.1 \mathrm{~s}$ \\
\hline & & & & BUN & $42.1 \mathrm{mg} / \mathrm{dl}$ & $\operatorname{IgG}$ & $1,999 \mathrm{mg} / \mathrm{dl}$ & $\mathrm{PT}$ & $88.0 \%$ \\
\hline & & & & $\mathrm{TP}$ & $6.4 \mathrm{~g} / \mathrm{dl}$ & $\operatorname{IgA}$ & $458 \mathrm{mg} / \mathrm{dl}$ & D-dimer & $1.81 \mu \mathrm{g} / \mathrm{dl}$ \\
\hline & & & & ALB & $3.2 \mathrm{mg} / \mathrm{dl}$ & $\operatorname{Ig} M$ & $148 \mathrm{mg} / \mathrm{dl}$ & Hyaluronic & \\
\hline & & & & UA & $6.0 \mathrm{mg} / \mathrm{dl}$ & ANA & 320 times & acid & $389.9 \mathrm{ng} / \mathrm{ml}$ \\
\hline & & & & $\mathrm{NH}_{3}$ & $221 \mu \mathrm{g} / \mathrm{dl}$ & SMA & negative & Type IV & \\
\hline & & & & $\mathrm{Ca}$ & $10.1 \mathrm{mg} / \mathrm{dl}$ & AMA & negative & collagen $7 \mathrm{~S}$ & $6.6 \mathrm{ng} / \mathrm{ml}$ \\
\hline & & & & $\mathrm{P}$ & $3.7 \mathrm{mg} / \mathrm{dl}$ & AMA2 & negative & & \\
\hline & & & & $\mathrm{Na}$ & $140 \mathrm{mEq} / \mathrm{l}$ & Intact & & & \\
\hline & & & & & & PTH & $87 \mathrm{pg} / \mathrm{ml}$ & & \\
\hline
\end{tabular}

neu. $=$ Neutrophil. 


\section{Case Reports in \\ Nephrology and Urology}

\begin{tabular}{l|l}
\hline \multicolumn{2}{l}{ Case Rep Nephrol Urol 2013;3:28-33 } \\
\hline DOI: 10.1159/000350908 & $\begin{array}{l}\text { ○ 2013 S. Karger AG, Basel } \\
\text { www.karger.com/cru }\end{array}$ \\
\hline
\end{tabular}

Yasukawa et al.: Chronic Portal-Systemic Shunt Encephalopathy in a Hemodialysis

Patient Treated with Balloon-Occluded Retrograde Transvenous Obliteration

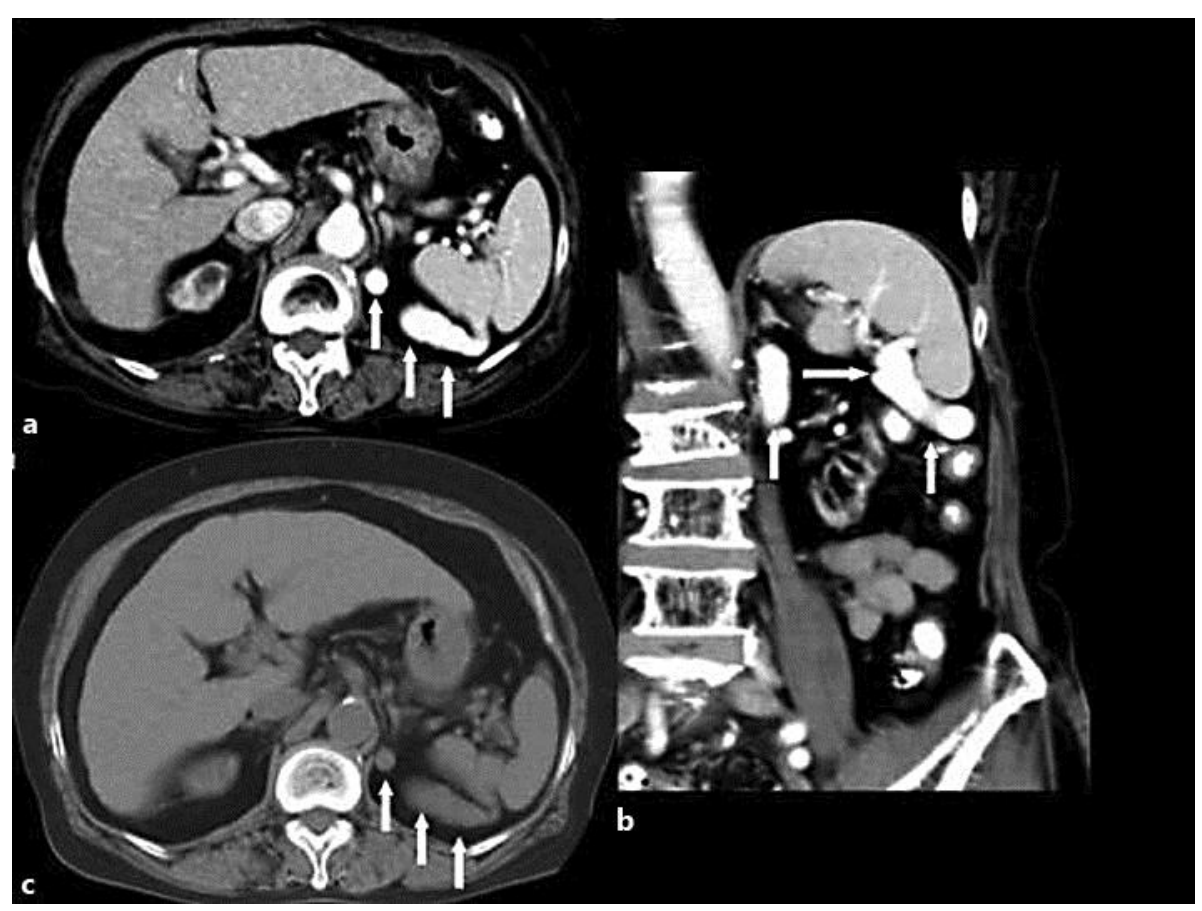

Fig. 1. Abdominal computed tomography. Arrows indicate shunt. Shunt diameter at admission (a, b - with b having been prepared from a) is equal to that from 7 years prior (c).

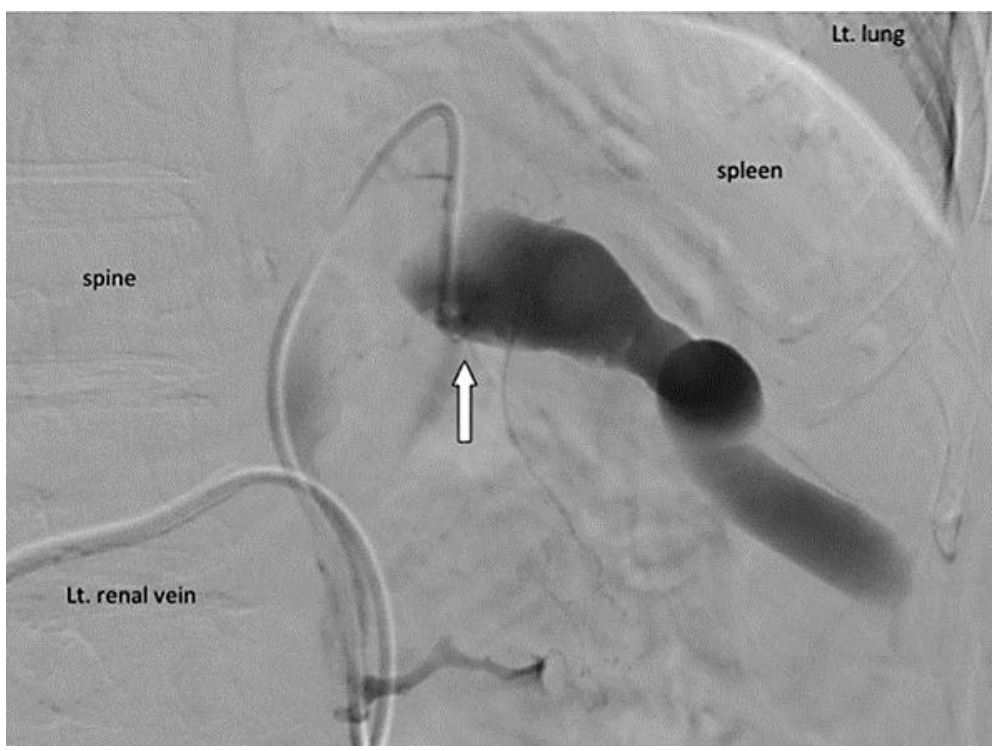

Fig. 2. Angiogram of B-RTO. A catheter is successively inserted into the right femoral vein, inferior vena cava, left renal vein, and shunt. Subsequently, the proximal region is occluded with a balloon (arrow), and the distal region is embolized with ethanolamine oleate. 